\title{
Developmental aspects of the effects of spinal cord transection upon audiogenic seizures in mice
}

\author{
JAMES F. WILLOTT \\ Northern Illinois University, DeKalb, Illinois 60115
}

\begin{abstract}
The contributions of somatic sensory and motor processes during audiogenic seizures were investigated in mice. Subjects were $395 \mathrm{DBA} / 2 \mathrm{~J}$ mice which received either complete transection of the lower thoracic spinal cord or an identical sham operation without actual cordotomy. Additional control procedures were also employed to detect "side effects" of surgery. Paraplegic mice, lacking substantial input from the posterior body, were compared with control mice for seizures. Postoperative intervals of $1 \mathrm{~h}, 1$ day, 4-5 days, or 12 days were used in mice of various ages. Convulsions cephalad to paralysis were studied in two experiments. In 21 day-old-mice (at the ontogenic peak of susceptibility to audiogenic seizures), paraplegic subjects had substantially reduced incidences of wild-running attacks, clonic-tonic convulsions, and fatalities induced by a 95-dB SPL noise band (Experiment 1). In contrast to 21-day-olds, younger and older paraplegic mice did not differ from their respective control mice in seizure incidence. In fact, there was a tendency for paraplegic mice to be more susceptible to audiogenic seizures at these ages (Experiment 2). The findings indicate that interruption of spinal cord pathways influenced paroxysmal activity in the brain, and this influence was related to ontogenic factors.
\end{abstract}

It is well established clinically and experimentally that somatic sensory stimuli and/or body movements may precipitate convulsions of various types (Arseni, Stoica, \& Serbanescu, 1967; Bickford \& Klass, 1969; Kreindler, 1960; Servit, 1963). However, the possible contribution of somatic processes to seizures which do not involve somatic precipitation is unclear. Since convulsions are characterized by dramatic motor manifestations, it would seem valuable to determine if, and how, somatic processes may in turn influence ongoing paroxysmal activity by afferent feedback or other mechanisms.

The present study is one of a series which utilizes sound-induced (audiogenic) seizures in the mouse to investigate the role of somatic sensory and motor processes in convulsions. Recent experiments showed that restraint of certain body movements was effective in reducing the incidence of fatal audiogenic seizures (Willott, 1974) and nonfatal generalized audiogenic clonic-tonic convulsions (Willott, 1976b). Another study (Willott, 1976a) utilized mice which had been given hemisection of the midthoracic spinal cord. Audiogenic seizures were subsequently induced monotonically by occlusion of one ear during exposure to sound (cf. Ward \& Collins, 1971). Mice with hemicordotomy ipsilateral to the patent (sound exposed) ear had less severe seizures than mice with contralateral

This research was performed in the Department of Psychology, University of California, Davis, and was part of the author's doctoral dissertation. The work was supported by National Institute of Neurological Disease and Stroke Grant NS-11565 to K. R. Henry, for which the author is grateful. hemicordotomy, which did not differ from controls. These findings suggest that activity in certain sensory and/or motor pathways of the spinal cord have centripetal influences upon sound-induced seizure activity in the CNS. The experiments to be described extend these findings by giving mice complete lower thoracic spinal cordotomy. Experiment 1 utilized mice which were at the ontogenic peak of susceptibility to audiogenic seizures, as in previous studies. Experiment 2 examined developmental factors by using mice at the ontogenic onset or decline of susceptibility.

\section{EXPERIMENT 1}

\section{Method}

The procedure in all experiments was to surgically section the lower thoracic spinal cord and test for seizures cephalad to paralysis at various postoperative intervals. This operation renders an animal paraplegic but leaves intact innervation of the intercostal muscles and most autonomic ganglia. Wild-running fits are still possible, and clonic-tonic convulsions may be readily observed in the eyes, pinnae, front limbs, and torso of such paraplegic mice.

Subjects. Twenty-one-day-old mice which were the offspring of DBA/2J mice from the Jackson Laboratory were used as subjects. This strain is naturally susceptible to audiogenic seizures from about 15 to 30 days of age, with peak susceptibility at 21 days (Schlesinger, Boggan, \& Freeman, 1965). Animals were maintained under ad-lib access to Purina Mouse Chow and tap water after weaning at age 20 days. A fixed lighting schedule was maintained.

Surgery. Spinal cord transection at the lower thoracic level is a relatively simple operation in the young mice used in the present study. The vertebral column lies just under the skin at that level and is invested with very little soft tissue. Since the bones are quite soft and transparent in young mice, laminotomy can be performed with a light scalpel incision. 
Operations were performed under ether anesthesia, since the surgical procedure could be completed relatively quickly, and mice recover susceptibility to seizures about $15 \mathrm{~min}$ after etherization.

An anesthetized mouse was placed on the operating surface, a midsagittal skin incision was made above the thoracic vertebrae, and the skin was retracted. The vertebral column was held posterior to the incision site with modified forceps, and laminotomy was made by a careful incision with a No. 11 scalpel blade at one of the lower five thoracic vertebrae. The blade tip was carefully inserted through the incision into the exposed dorsal surface of the spinal cord, and a complete transverse section of the cord was made. A small amount of bleeding frequency occurred at this point, and cauterization was used to arrest it immediately. Cauterization was applied to all subjects, whether or not it was needed, in order to standardize the procedure. The skin incision was then closed with sutures or wound clips, and the subject was allowed to recover.

Control sham operations were performed in the same manner, but the spinal cord was not transected. The bone incision was cauterized as a control procedure, but rarely needed it. To approximate the small amount of bleeding in their paraplegic counterparts, the tips of the tails of the control mice were amputated.

Operations were considered acceptable if both hindlimbs were completely paralyzed, there was no response to pinching the hindlimbs or tail, and the animal appeared to have otherwise normal vitality. The vast majority of operations met these criteria, since the transections could be easily visualized and controlled during surgery. Many subjects were, in addition, sacrificed for histological verification of the transections.

Operation-test intervals. Since most mice remain susceptible to audiogenic seizures for only about 2 weeks of their lives, long postoperative recovery periods were not possible. However, the relative ease of surgery and apparent rapid recovery reduced this problem greatly.

Mice in this experiment were tested for seizures at 21 days of age, the ontogenic peak of susceptibility to audiogenic seizures (Schlesinger et al., 1965). The subjects received surgery $1 \mathrm{~h}, 1$ day, or 4-5 days prior to seizure testing. The subjects were tested only once to prevent sensitization to audiogenic seizures by acoustic priming (Henry, 1967).

During the operation-test interval, food and water were made available at the floors of the cages to allow paraplegic mice easy access to it. Weanling paraplegic mice seemed to have no problem obtaining and eating food.

To control for handling, stress, etc., all subjects of a given experimental group were handled and anesthetized equivalently.

Induction of seizures. Seizures were induced in a test chamber which has been described in detail elsewhere (Willott, Henry, \& George, 1975). It consisted of an upright clear Plexiglas cylinder on top of which was an Altec tweeter. The seizure-inducing stimulus was a filtered white noise band of $10-20 \mathrm{kHz}$, whose intensity could be controlled with an attenuator. Intensity was initially calibrated by placing the microphone of a Bruël and Kjaer SPL meter in an opening at the bottom of the chamber. The chamber was housed in a second-attenuated box which had a window for viewing subjects.

Mice were placed individually into the test chamber. The sound was activated, and latencies to the stages of the seizure syndrome were measured with a stopwatch (wild-running attack, clonic convulsion, tonic convulsion, respiratory failure). Most seizures were induced with a noise intensity of $95 \mathrm{~dB}$ SPL (re: $20 \mathrm{~N} / \mathrm{m}^{2}$ ). This is sufficiently above the minimal seizure-inducing intensity (about $90 \mathrm{~dB}$ ) to consistently produce maximal convulsions in the mice used in this study. Some subjects, as noted, were tested with $110 \mathrm{~dB}$ SPL. All testing was done in the early afternoon to control for circadian rhythms.

Control procedures. Experimental lesion studies always run the risk of accompanying "side effects" which may affect sub- jects' behavior irrespective of the intended effects of the surgery. This is especially true with audiogenic and electroshock seizures, since they may be influenced by such factors as anesthesia, body temperature, diet, anoxia, acid-base balance, and other variables (Bevan, 1955; Finger, 1947; Lehmann \& Busnel, 1963; Willott \& Henry, 1976). Accordingly, the following control procedures were instituted.

(1) As described, sham-operate littermates received similar treatment to that of operates in all experiments. In addition, 28 mice were given low (lumbosacral) spinal cordotomies, which result in little detectable paralysis.

(2) Various intervals between operations and testing for seizures were used to indicate the presence of variables associated with surgery, such as "trauma," residual anesthesia, etc. If experimental results were related to postoperative recovery time per se, the presence of such side effects would be suggested.

(3) Weights and body temperatures were measured for many subjects to indicate any significant changes in these variables.

(4) To uncover gross abnormalities in brain function, EEG and auditory "far field" evoked responses were recorded. The latter responses, described by Jewett, Romano, and Williston (1970) are believed to originate from subcortical stations of the auditory pathway. For EEGs, an active stainless steel electrode was placed epidurally over the midbrain, and a grounded "reference" electrode was placed near the frontal sinus in six alert, partially restrained mice. Auditory far-field recordings were obtained from eight barbiturate-anesthetized mice with a silver wire electrode placed epidurally over the vertex. Click stimuli were presented at $90 \mathrm{~dB}$ SPL and $10 / \mathrm{sec}$, and evoked potentials were averaged with a Tracor Northern NS-575A signal analyzer.

\section{Results}

Audiogenic seizures. At all operation-test intervals, 21-day-old paraplegic mice were less likely to have clonic-tonic convulsions cephalad to paralysis compared to controls. In addition, if convulsions occurred, they were less likely to end fatally in paraplegic mice. As seen in Table $1,1 \mathrm{~h}$ after surgery, the incidence of clonic-tonic convulsions in paraplegic mice was reduced by $23 \%$ (Fisher exact probability $=0.048$ ), incidence of wild-running attacks (i.e., all seizure activity) was reduced by $21 \%$ (Fisher exact probability $=0.035$ ), and fatal convulsions were reduced by $76 \%$ (Fisher exact probability $=0.0000003$ ).

For paraplegic mice tested for seizures 1 day after surgery, there was a $45 \%$ reduction in clonic-tonic convulsions (Fisher exact probability $=0.0002$ ), a $35 \%$ reduction in wild-running attacks (Fisher exact probability $=0.0004$ ), and a $60 \%$ reduction in fatalities (0.000003). Finally, paraplegic mice receiving surgery 4-5 days before testing showed $35 \%$ fewer fatalities $\left(\chi^{2}=7.841, \mathrm{p}<.01\right), 20 \%$ fewer clonic-tonic convulsions $\left(\chi^{2}=3.262, .05\right.$ $<\mathrm{p}<.10$ ), and $20 \%$ fewer wild-running attacks $\left(\chi^{2}=5.896, \mathrm{p}<.02\right) .^{1}$ The incidences of convulsions and fatalities did not statistically differ as a function of the postoperative interval (Fisher exact probabilities $>.05$ ).

Not surprisingly, audiogenic seizures induced with more intense, 110-dB SPL, noise were more severe than those induced with $95 \mathrm{~dB}$. As seen in Table 1, 
Table 1

Incidence of Audiogenic Seizures in 21-Day-Old Mice

\begin{tabular}{|c|c|c|c|c|c|}
\hline $\begin{array}{l}\text { Operation-Test Interval } \\
\text { (Days) }\end{array}$ & Condition & $\mathbf{N}$ & $\begin{array}{l}\text { Percent } \\
\text { Deaths }\end{array}$ & $\begin{array}{c}\text { Percent } \\
\text { Clonic-Tonic }\end{array}$ & $\begin{array}{c}\text { Percent } \\
\text { Wild Running }\end{array}$ \\
\hline Op 21 Test $+1 \mathrm{~h}$ & $\begin{array}{l}\text { Paraplegic } \\
\text { Control }\end{array}$ & $\begin{array}{l}24 \\
21\end{array}$ & $\begin{array}{l}0^{*} \\
76\end{array}$ & $\begin{array}{l}67 * \\
90\end{array}$ & $\begin{array}{l}79 * \\
100\end{array}$ \\
\hline Op 20 Test 21 & $\begin{array}{l}\text { Paraplegic } \\
\text { Control } \\
\text { Low Cordot. }\end{array}$ & $\begin{array}{l}34 \\
26 \\
28\end{array}$ & $\begin{array}{l}21^{*} \\
81 \\
79\end{array}$ & $\begin{array}{l}47^{*} \\
92 \\
82\end{array}$ & $\begin{array}{l}65^{*} \\
100 \\
100\end{array}$ \\
\hline Op 20 Test $21(110 \mathrm{~dB})$ & $\begin{array}{l}\text { Paraplegic } \\
\text { Control }\end{array}$ & $\begin{array}{l}10 \\
10\end{array}$ & $\begin{array}{l}10 * \\
80\end{array}$ & $\begin{array}{l}100 \\
100\end{array}$ & $\begin{array}{l}100 \\
100\end{array}$ \\
\hline Op 16-17 Test 21 & $\begin{array}{l}\text { Paraplegic } \\
\text { Control }\end{array}$ & $\begin{array}{l}35 \\
36\end{array}$ & $\begin{array}{l}45^{*} \\
80\end{array}$ & $\begin{array}{l}68 \\
88\end{array}$ & $\begin{array}{l}80^{*} \\
100\end{array}$ \\
\hline
\end{tabular}

*Probability of paraplegic $=$ control $<.05$. See text for exact values.

in both operates and controls, wild-running and clonic-tonic convulsions occurred in $100 \%$ of the mice tested with $110 \mathrm{~dB}$. It would appear that the protective effect of cordotomy was "overridden" by increasing the intensity of the seizure-inducing stimulus. However, fatalities were still markedly reduced in paraplegic mice by $70 \%$ (Fisher exact probability $=0.003$ ).

Latencies and durations of seizure components. As measured with a stopwatch and visual observation, no significant differences in latencies to the onset of audiogenic wild-running attacks or clonictonic convulsions were observed between operates and controls in any age groups. Latencies to onset of wild-running attacks were typically between 4 and $5 \mathrm{sec}$. The time from onset of wild running to tonic extension was comparable for all mice regardless of age or surgery and was usually between 8 and $9 \mathrm{sec}$. In convulsions ending fatally, the length of time spent in tonic extension before respiratory failure was greater in operates than in controls. For instance, when tested at $110 \mathrm{~dB}$, control subjects had fatal tonic extensions lasting for a mean of $13.1 \mathrm{sec}$, whereas cordotomized subjects had a mean of $16.8 \mathrm{sec}$ in tonic extensions ending fatally $(t=$ $2.892, \mathrm{df}=22, \mathrm{p}<.01$ ).

Control procedures. Taken together, the results of control procedures do not indicate that any significant side effects of surgery were factors in the data thus far presented.

Temperatures of paraplegic mice tended to be slightly (less than $1^{\circ} \mathrm{C}$ ) lower than those of control mice, and one group of operates significantly differed from controls. Twenty-one-day-old control mice had a mean body temperature of $37.9^{\circ} \mathrm{C}$, compared to $37.0^{\circ} \mathrm{C}$ for operates receiving surgery on Day $20(\mathrm{t}=3.308, \mathrm{df}=23, \mathrm{p}<.01)$. Despite the fact that severe hypothermia may reduce susceptibility to audiogenic seizures (Essman \& Sudak, 1964; Fuller \& Rappaport, 1952), a small reduction of body temperature has been shown to have no effect upon seizure incidence (Willott, 1974).
Body weights of paraplegic mice tended to be lower $(5 \%$ to $14 \%)$ than those of controls after 1 or more days of postoperative recovery. Point-biserial correlations, however, showed no significant correlation between body weight and seizures among paraplegic mice. For instance, a coefficient of 0.226 was obtained between clonic-tonic convulsions and body weight in paraplegic mice recovering for more than 1 day, and a coefficient of 0.071 was obtained for weight vs. fatalities. The slight weight loss of paraplegic mice can probably be accounted for by atrophy of the hindquarters, rather than poor diet or health. Paraplegic mice appeared to nurse or eat food competitively with controls, and weight losses persisted indefinitely.

Electrophysiological recordings were indistinguishable for paraplegic and control mice, with regard to latencies, amplitudes, or waveforms.

As demonstrated above, there were no consistent differences in incidences of convulsions as a function of postoperative recovery time per se. Also, sham-operate controls and lumbosacral operates had typical seizure incidence and severity at all recovery periods (Table 1). These findings indicate that nonspecific side effects of surgery were not important factors.

\section{Discussion}

It appears that the severity of sound-induced convulsions was affected by surgical transection of the spinal cords of 21-day-old mice. Cordotomy was clearly associated with lower incidence and severity of audiogenic seizures cephalad to paralysis, when induced with 95-dB noise band. In light of the control procedures described, it seems reasonable to assume that the reduction of seizures was related to the interruption of spinal cord pathways. While both specific and nonspecific pathways would be affected by cordotomy, it should be noted that the protective effect of cordotomy upon audiogenic seizures has previously been shown to be lateralized by inducing seizures monotically in mice which had 
Table 2

Incidence of Audiogenic Seizures in Younger and Older Mice

\begin{tabular}{clcccc}
\hline Operation-Test Interval & Condition & N & $\begin{array}{c}\text { Percent } \\
\text { Deaths }\end{array}$ & $\begin{array}{c}\text { Percent } \\
\text { Clonic-Tonic }\end{array}$ & $\begin{array}{c}\text { Percent } \\
\text { Wild Running }\end{array}$ \\
\hline \multirow{2}{*}{ Op 16-17 Test + 1 h } & Paraplegic & 24 & 46 & 71 & 88 \\
& Control & 25 & 40 & 48 & 84 \\
Op 15 Test 16 (1 Day) & Paraplegic & 15 & 47 & 80 & 87 \\
& Control & 14 & 50 & 57 & 93 \\
Op 28-29 Test + 1 h & Paraplegic & 17 & 0 & 76 & 76 \\
& Control & 15 & 27 & 53 & 100 \\
Op 28-29 Test + 1 Day & Paraplegic & 14 & $7 *$ & 64 & 64 \\
Op 16-17 Test 28-29 & Control & 15 & 40 & 60 & 87 \\
& Paraplegic & 16 & 25 & 69 & 81 \\
\hline
\end{tabular}

*Probability of paraplegic $=$ control $=.045$.

been given only hemisection of the spinal cord. The effect of hemicordotomy depended upon whether the ipsilateral or contralateral ear was stimulated to induce seizures, suggesting the involvement of specific pathways (Willott, 1976a). Also suggesting a role of specific sensory pathways is the finding of Bevan and Hunt (1953) that lesions to the dorsal column nuclei of rats reduced audiogenic seizures.

The data obtained thus far are consistent with previous findings, in that interfering with body movement was associated with less severe audiogenic seizures. Since demonstrations of this effect have thus far been on mice which were at the ontogenic peak of susceptibility to audiogenic seizures, the following experiment was performed to examine developmental aspects of this phenomenon.

\section{EXPERIMENT 2}

For a more thorough understanding of the protective effect of paraplegia upon audiogenic seizures, developmental variables need to be considered. Ontogenic factors are of great importance in determining susceptibility to audiogenic seizures, so it was necessary to study the effects of cordotomy as a function of development. Consequently, the previous experiment was replicated with mice which were at the ages of ontogenic onset of susceptibility (15-16 days) or ontogenic decline of susceptibility (28-29 days).

\section{Method}

The same methods were employed as in Experiment 1, except that different aged DBA/2J mice were used. Mice tested for seizures at age 16 days received surgery either 1 day or $1 \mathrm{~h}$ before testing. Mice tested at age 28-29 days received surgery $1 \mathrm{~h}, 1$ day, or 12 days before testing.

\section{Results}

Table 2 shows that the protective effects of cordotomy on clonic-tonic convulsions observed in the 21-day-olds of Experiment 1 were not seen in the younger or older mice of this experiment. In fact, for most groups, paraplegic mice tended to be more likely to have clonic-tonic convulsions than controls. Of younger subjects receiving surgery $1 \mathrm{~h}$ or 1 day before testing, $23 \%$ more paraplegics had clonictonic convulsions than did controls (Fisher exact probabilities $=0.064$, and 0.14 , respectively). Similar increases in the percentages of paraplegic mice having clonic-tonic seizures were also observed in older mice. While none of these differences were significant at the .05 level (Fisher exact probabilities), many closely approached probabilities of 0.1 . The effect of development upon clonic-tonic seizures in paraplegic mice is shown in Figure 1.

In contrast with clonic-tonic seizures, the data on fatalities are in accord with those of Experiment 1. Despite the fact that paraplegic mice were not less likely than controls to have clonic-tonic seizures, the percentage of such convulsions ending fatally was lower in paraplegics. For 28-29-day-old paraplegic mice, only 5 of 33 clonic-tonic convulsions $(15 \%)$ ended in death. For their control counterparts, 15 of 24 clonic-tonic convulsions $(63 \%)$ ended fatally (Fisher exact probability $=0.002$ ). A similar finding was observed in younger mice, where $62 \%$ of clonictonic seizures ended in death in paraplegics vs. $85 \%$ in controls (Fisher exact probability $=0.058$ ).

To summarize, the effects of spinal cordotomy upon clonic-tonic seizures were related to age at testing. Twenty-one-day-old paraplegic mice were less likely than controls to have clonic-tonic convulsions (Experiment 1). However, the same operation had either no effect or perhaps the opposite effect in younger and older mice. At all ages, if clonic-tonic convulsions occurred, they were less likely to end fatally in paraplegic mice.

\section{DISCUSSION}

While Experiment 1 supports previous findings that interfering with somatic processes diminishes audiogenic seizures, the ontogenic aspects of this phenomenon seen in Experiment 2 were unexpected 

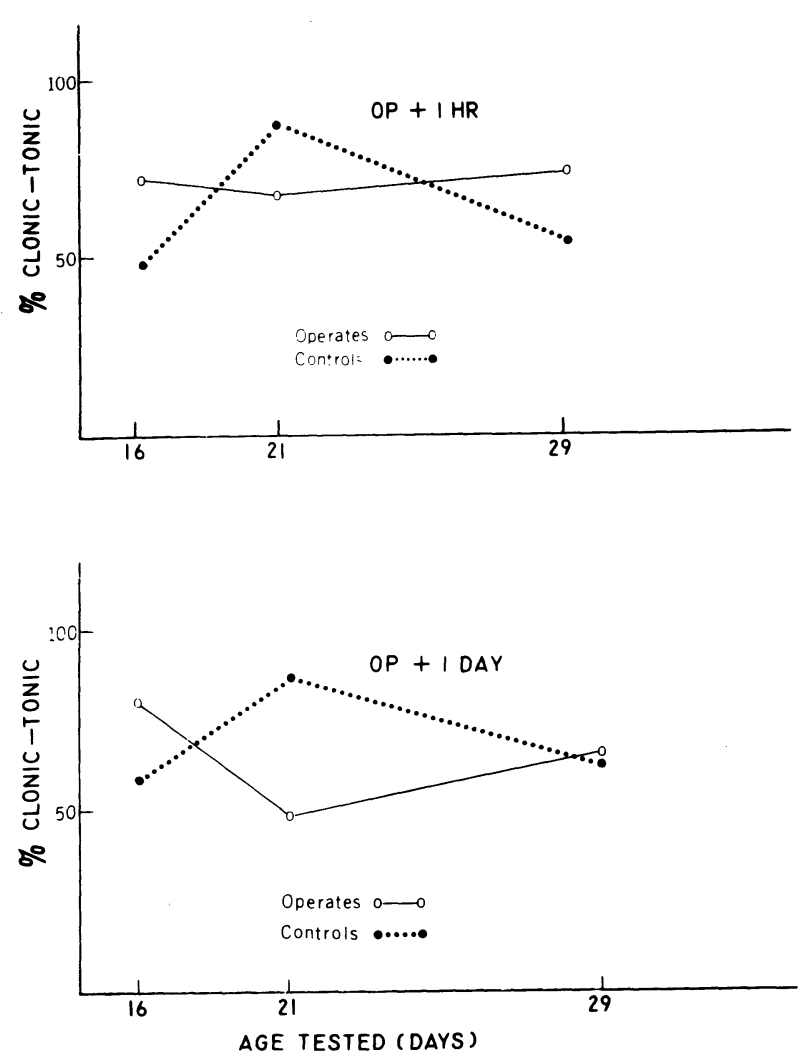

Figure 1. Effects of cordotomy upon audiogenic seizures in mice of three different ages. Lines connecting points are for graphic clarity and should not be construed as implying seizure susceptibility between points. Note that control animals show peak susceptibility at 21 days of age which is characteristic of the DBA/2J strain. Paraplegic mice at this age, however, are markedly less likely to have clonic-tonic convulsions.

and seemingly paradoxical. One might predict that convulsions would be more easily prevented in the less susceptible younger and older mice. In fact, the opposite occurred as seizures in these animals were resistant to the protective effects of cordotomy. Paraplegic mice at these ages may even have been more susceptible to audiogenic seizures, although this effect was not quite statistically significant. This finding is difficult to explain. It is possible that some parameters of neural activity are related to developmental factors in a way that would result in their having different effects upon seizures. Observations of Schlesinger, Boggan, and Freeman (1965) are of interest in this regard. They found that DBA/ $2 J$ mice had reduced levels of brain norepinephrine and serotonin only at age 21 days. By contrast, 14day-old and 28-day-old mice had levels of these substances which did not differ from nonsusceptible C57BL/6J mice. Both norepinephrine and serotonin have been associated with susceptibility to audiogenic seizures in a variety of experiments (Lehmann, 1970; Schlesinger \& Griek, 1970). It is not clear if these findings are directly related to those of the present study, but they do suggest the possibility of an interaction between biochemical variables, the developing mouse brain, and parameters of somatic sensory input.

It is notable that fatal clonic-tonic convulsions were reduced in paraplegic mice at all ages, regardless of relative susceptibility to convulsions. Also, in Experiment 1, seizures induced with $110-\mathrm{dB}$ noise readily occurred in paraplegic mice, but deaths were still much less likely. These findings suggest that the risk of seizure fatalities may be related more to paralysis per se than to the severity of seizures. This does not seem unreasonable, since seizure fatalities are, in part, caused by depletion of $\mathrm{O}_{2}$ and other metabolites during convulsions (Willott \& Henry, 1976). Since neural and muscular tissue below cordotomies did not participate in convulsions, the overall metabolic depletion would be reduced during seizures in paraplegic mice, perhaps protecting them from death. Therefore, caution should be used in interpreting fatalities to indicate more severe seizure activity than nonfatal seizures. Rather, fatalities may be related to greater susceptibility to anoxia and metabolic depletion.

The findings reported here provide evidence that the interruption of nonspecific and/or specific pathways associated with posterior body movements affected audiogenic seizures cephalad to cordotomies. While this effect was somehow related to developmental factors, it was clearly evident in 21-day-old mice. An implication of these findings is that sensory input from the body may be of some importance in the development of central paroxysmal activity through feedback from convulsive movements, the imposition of atypical patterns of somatosensory input, or other mechanisms. While one may not generalize from mouse audiogenic seizures to other types of convulsions, the speculation is inescapable that perhaps such mechanisms have more widespread importance than is commonly assumed, and may play a role in other types of seizures.

\section{REFERENCES}

Arseni, C., Stoica, I., \& Serbanescu, T. Electro-clinical investigations on the role of proprioceptive stimuli in the onset and arrest of convulsive epileptic paroxysms. Epilepsia, 1967, 8. 162-170.

Bevan, W. Sound-precipitated convulsions: 1947 to 1954. Psychological Bulletin, 1955, 52, 473-504.

Bevan, W., \& Hunt, E. L. Proprioceptive inflow and susceptibility to experimentally induced seizures. Journal of Comparative and Physiological Psychology, 1953, 46, 218-224.

Bickford, R. G., \& Klass, D. W. Sensory precipitation and reflex mechanisms. In H. H. Jasper, A. A. Ward, Jr., \& A. Pope (Eds.), Basic mechanisms of the epilepsies. Boston: Little, Brown, 1969. Pp. 543-564.

Essman, W. B., \& SudAK, F. N. Audiogenic seizures in genetically susceptible mice: Relation of hypothermia to onset and susceptibility. Experimental Neurology, 1964, 9, 228-235. 
Finger, F. W. Convulsive behavior in the rat. Psychological Bulletin, 1947, 44, 201-248.

Fuller, J. L., \& RAppaport, A. The effect of wetting on sound induced convulsions in mice. Journal of Comparative and Physiological Psychology, 1952, 45, 246-249.

HENRY, K. R. Audiogenic seizure susceptibility induced in C57BL/6J mice by prior auditory exposure. Science, 1967, 158, 938-940.

Jewett, D. L., Romano, N. N., \& Williston, J. S. Human auditory evoked potentials: Possible brainstem components detected on the scalp. Science, 1970, 167, 1517-1518.

Kreindler, A. Experimental epilepsy. Progress in Brain Research, 1960, 19, 219.

Lehmann, A. G. Psychopharmacology of the response to noise, with special reference to audiogenic seizures in mice. In B. L. Welch \& A. S. Welch (Eds.), Physiological effects of noise. New York: Plenum Press, 1970. Pp. 227-257.

Lehmann, A. G., \& Busnel, R. G. A study of the audiogenic seizure. In R. G. Busnel (Ed.), The acoustic behavior of animals. New York: Elsevier, 1963. Pp. 244-274.

Schlesinger, K., Boggan, W., \& Freeman, D. X. Genetics of audiogenic seizures: I. Relation to brain serotonin and norepinephrine in mice. Life Sciences, 1965, 4, 2345-2351.

SChlesinger, K., \& GrieK, B. J. The genetics and biochemistry of audiogenic seizures. In G. Lindzey \& D. D. Thiessen (Eds.), Contributions to behavior-genetic analysis: The mouse as a prototype. New York: Appleton-Century-Crofts, 1970. Pp. 219-257.

SERVIT, Z. (Ed.) Reflex mechanisms in the genesis of epilepsy. New York: Elsevier, 1963.
WARD, R., \& Collins, R. L. Asymmetric audiogenic seizures in mice: A possible analogue of focal epilepsy. Brain Research, 1971, 31, 207-210.

Willotr, J. F. Protection from lethal audiogenic seizures in mice by physical restraint of movement. Experimental Neurology, 1974, 43, 359-368.

WILlotT, J. F. The effects of unilateral spinal cordotomy and outer ear occlusion on audiogenic seizures in mice. Experimental Neurology, 1976, 50, 30-35. (a)

WILlOTT, J. F. The role of sensory processes in audiogenic seizures in mice. PhD dissertation, University of California, Davis, 1976. (b)

Willott, J. F., Henry, K. R., \& George, F. Noise-induced hearing loss, auditory evoked potentials, and protection from audiogenic seizures in mice. Experimental Neurology, 1975, 46, $542-553$.

Willott, J. F., \& HenRy, K. R. The roles of anoxia and noiseinduced hearing loss in the postictal refractory period for audiogenic seizures in mice. Journal of Comparative and Physiological Psychology, 1976, 90, 373-381.

\section{NOTE}

1. Chi-square tests were used because of large $\mathrm{N}$.

(Received for publication December 17, 1975; revision accepted December 28, 1976.) 